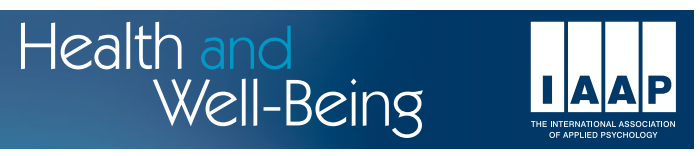

APPLIED PSYCHOLOGY: HEALTH AND WELL-BEING, 2020

doi:10.1111/aphw.12223

\title{
Belief in COVID-19 Conspiracy Theories Reduces Social Distancing over Time
}

\author{
Kinga Bierwiaczonek* (iD \\ University of Oslo, Oslo, Norway \\ VU University Amsterdam, The Netherlands \\ Jonas R. Kunst and Olivia Pich \\ University of Oslo, Oslo, Norway
}

\begin{abstract}
Background: Conspiracy theories about the origins of COVID-19 are widespread and have even been propagated by highly ranked state officials and politicians in the US. Health authorities have cautioned that such theories, although not questioning the existence of the pandemic, may increase the spread of the virus by reducing people's efforts to socially distance. Methods: We test this proposition empirically using longitudinal survey data collected at five timepoints during the early outbreak of the virus in the US $(N=403)$. Results: Multivariate growth curve analyses showed that, although conspiracy beliefs decreased and social distancing increased over time, people holding more conspiracy beliefs at the beginning of the pandemic showed the lowest increase in social distancing. Moreover, cross-lagged analyses demonstrated that people who reported more conspiracy beliefs at any wave tended to report less social distancing at the following wave. Conclusions: Our findings show that COVID-19 conspiracy theories pose a significant threat to public health as they may reduce adherence to social distancing measures.
\end{abstract}

Keywords: conspiracy theories, COVID-19, longitudinal, social distancing

\section{INTRODUCTION}

The COVID-19 pandemic has forced billions of people around the world to stay at home and reduce their social interactions to a minimum, thereby adhering to a coordinated effort to contain the spread of the virus. At the same time, these unprecedented social distancing measures have been challenged by an unmatched amount of conspiracy theories and fake news on the origin and

*Address for correspondence: Kinga Bierwiaczonek, Department of Psychology, University of Oslo, Postboks 1094, Blindern, 0317 Oslo, Norway. Email: k.m.bierwiaczonek@psykologi.uio.no The authors declare that they do not have any conflicts of interest regarding the research reported in the current paper.

(C) 2020 The Authors. Applied Psychology: Health and Well-Being published by John Wiley \& Sons Ltd on behalf of International Association of Applied Psychology

This is an open access article under the terms of the Creative Commons Attribution-NonCommercial License, which permits use, distribution and reproduction in any medium, provided the original work is properly cited and is not used for commercial purposes. 
severity of the virus, pushing the World Health Organization to declare it an infodemic (World Health Organization [WHO], 2020a). In some countries such as the US, which currently has the most confirmed COVID-19 cases (WHO, 2020b), conspiracy theories have even been propagated by state officials, and an alarming one-third of all US inhabitants seem to believe in theories such as that the virus was manufactured on purpose (Uscinski \& Enders, 2020). Health officials have warned of the potentially severe consequences of such conspiracy theories as they may distract people from social distancing efforts (BBC News, 2020a). Given the urgency of the topic, several researchers are working on investigating this potential process (see, for instance, preprints by Imhoff \& Lamberty, 2020; Swami \& Barron, 2020), but to the best of our knowledge, a longitudinal, well-powered test providing insights into potential causal mechanisms over time is lacking to date. Here, we provide such an investigation with data collected at five timepoints over the 6 crucial weeks of the early COVID-19 outbreak in the US - a time in which strict adherence to social distancing measures in retrospect could have saved many lives.

As of 3 April 2020, compulsory or recommended confinements, curfews, and quarantines were in place in more than 90 countries and territories, covering more than 3.9 billion people, or half of the world's population (Sandford, 2020). In the US, Donald Trump announced preventive measures including social distancing and self-isolation on 16 March 2020 (Sheikh, 2020), the first day of our data collection. Yet, the strictness and duration of these measures varied across states, with the first states announcing reopening as early as 20 April 2020, the last day of our data collection period. Importantly, the effectiveness of the social distancing measures relies on each individual adhering to them. However, a Gallup survey of 3,876 adult US citizens found considerable variation in social distancing, reporting that people were about equally likely to report self-isolating as not self-isolating between 16 and 19 March. Although the percentage of selfisolating individuals increased to 75 per cent around 3 April 2020 (McCarthy, 2020), a considerable number of people still chose not to adhere to these measures. Indeed, although most states had at least advisory social distancing measures in place at that time (Haffajee \& Mello, 2020), nonadherence rates remained close to 25 per cent, which is substantially higher than in many other countries (European Parliament, 2020). For instance, one survey found that, between 19 March and 29 March, 92-99 per cent of respondents from Italy, Germany, and the Netherlands adhered to different types of social distancing measures (Meier et al., 2020). What then can explain the relatively high nonadherence in the US? We argue and aim to empirically demonstrate that one important cause may be the widespread belief in conspiracy theories surrounding COVID-19.

Conspiracy theories, defined as explanatory beliefs about a group of actors that collude in secret to reach malevolent goals (Bale, 2007; Van Prooijen \& Douglas, 2018), tend to gain momentum during societal crises such as natural

(C) 2020 The Authors. Applied Psychology: Health and Well-Being published by John Wiley \& Sons Ltd on behalf of International Association of Applied Psychology 
disasters, war or pandemics (Van Prooijen \& Douglas, 2017, 2018; also see Van Bavel et al., 2020). Indeed, already in January 2020, the journal Nature published an Editor's note cautioning against the theory that the virus leaked from a biolab in Wuhan (Nature, 2020). Later into the outbreak, this "accidental leakage" theory became prominent and found support among politicians including the US Secretary of State Mike Pompeo and the US President Donald Trump, whose allegations resulted in international tensions (BBC News, 2020). Other conspiracy theories presented COVID-19 as deliberately bioengineered, a biological weapon, or a population control scheme.

In light of previous research and given the unprecedented scope and spread of conspiracy theories about COVID-19, there is reason to believe that their negative societal impact may be severe. Generally, conspiracy beliefs can undermine public support for government policies (Van Prooijen \& Douglas, 2018), decrease key predictors of voluntary compliance, such as perceived credibility of the powerful (Imhoff \& Bruder, 2014) or trust in authorities and institutions (see also Jolley \& Douglas, 2014a; Wahl, Kastlunger, \& Kirchler, 2010). Importantly, they can also undermine health-related preventive behaviors. For instance, believing in conspiracies around birth control is associated with less condom use (Bird \& Bogart, 2005); believing in HIV conspiracy theories with negative attitudes toward HIV medication (Bird \& Bogart, 2005; Gillman et al., 2013); and believing in anti-vaccine conspiracy theories with lower willingness to vaccinate one's child (Jolley \& Douglas, 2014b). Analogous effects could be expected in the context of COVID-19. If people endorse conspiracy beliefs, they may be less likely to adhere to state-supported measures such as social distancing guidelines. Such a process would be detrimental to public health, increasing the spread of the virus and endangering the lives of many.

Crucially, most empirically documented effects of conspiracy theories refer to behaviors that are logically implied by these theories, for example refusing to vaccinate one's children in response to the theory that vaccines have undisclosed health-damaging effects (Jolley \& Douglas, 2014b). In contrast, the most prevalent COVID-19 conspiracy theories, such as the accidental leakage or biological warfare theories, do not directly imply that taking preventive measures is unnecessary or harmful. Could these types of conspiracy theories that do not question the existence or the mortal peril of the virus per se still have a negative effect on social distancing? Conspiracy beliefs affect people's actions in part because they increase feelings of powerlessness that translate into disengaged behaviors (Jolley \& Douglas, 2014a, 2014b). Since any COVID-19 conspiracy theory may lead to such feelings, we expect that people endorsing the most widespread theories about the origin of the virus may also engage in less social distancing, risking their own and other people's health.

Against this background, in the current study we set out to test the potential negative effect that COVID-19 conspiracy theories, which are widespread but logically unrelated to prevention behaviors, may have on social distancing. We 
used data collected at five timepoints during the early outbreak of the virus in the US - a time in which social distancing measures would have been highly effective in preventing its spread. To gain causal insights, we combine multivariate growth curve modelling and cross-lagged models to analyse the data.

\section{METHOD}

\section{Participants and Procedure}

The present research was evaluated and exempted by a national center for research data in the country of the first author's main institution. Power analysis for a cross-lagged panel model with two constructs measured over five waves conducted in the R package bmem (Zhang, 2014) showed that 400 participants were needed do find a small lagged effect ( $r=0.15$, assuming stability coefficients of 0.60 ) with a power of 80 per cent. As to the latent growth model, Hertzog and colleagues (2006) estimated that the power for detecting a small slopeslope correlation $(r=0.20)$ exceeded 80 per cent with 500 participants and two constructs measured over five waves, assuming high reliability of growth. Considering that we were mostly interested in between slope-intercept correlations that are less statistically demanding than slope-slope correlations, we aimed at a sample of 400 participants.

Thus, we recruited 403 adult US citizens via Amazon's Mechanical Turk $\left(M_{\text {age }}=37.42, S D_{\text {age }}=11.14 ; 45.9 \%\right.$ were women $)$. All participants gave their informed consent prior to completing the questionnaire. Data collection took place in 2020 on 16 March for T1, on 23 March for T2, on 30 March for T3, on 6 April for T4, and on 20 April for T5. At each wave, participants were invited to complete the survey even if they had missed the previous wave. In total, 399 participants $(99 \%)^{1}$ completed the survey at T1, $273(67.7 \%)$ at T2, $281(69.7 \%)$ at T3, $257(63.8 \%)$ at $\mathrm{T} 4$, and $240(59.5 \%)$ at T5. Independent samples $t$-tests showed no differences on conspiracy beliefs and social distancing at any timepoint between participants who completed the five waves and participants who missed one or more waves (all $p s>.10$ ), suggesting random attrition. A majority of participants $(59.3 \%)$ had completed higher education (equivalent to a $4-$ year Bachelor's degree or higher), and 53.7 per cent reported having a household income of $\$ 50,000$ or more. The sample reflected the whole political spectrum, with 47.1 per cent of participants at T1 indicating being moderately to very liberal, 40.7 per cent reporting being moderately to very conservative, whereas 12.2 per cent of respondents positioned themselves at the center of the political spectrum. Most participants self-identified as Caucasian (73.4\%), 13.3 per cent

\footnotetext{
${ }^{1}$ Please note that although an initial sample of 403 participants were contacted at T1, due to a technical issue, responses for four participants were missing at T1.
}

(C) 2020 The Authors. Applied Psychology: Health and Well-Being published by John Wiley \& Sons Ltd on behalf of International Association of Applied Psychology 
as African American, 6 per cent as Hispanic, and the remaining group listed other ethnicities. Detailed demographics can be found in the supplementary online materials (SOM, Table S1).

\section{Measures}

Social Distancing. $\quad$ A three-item measure (T1: $\alpha=0.88 ; \mathrm{T} 2: \alpha=0.91 ; \mathrm{T} 3$ : $\alpha=0.89$; T4: $\alpha=0.91$; T5: $\alpha=0.90$ ) assessed participants' willingness to practice social distancing during the COVID-19 pandemic. The scale consisted of the following items: "I avoid in-person contact with others"; "I avoid attending social gatherings in person"; and "I try to keep a safe distance from others". Items were measured on a 7-point scale ranging from 1 (strongly disagree) to 7 (strongly agree).

Conspiracy Beliefs. Conspiracy beliefs concerning the COVID-19 pandemic were assessed using three items, capturing commonly shared conspiracy theories about the pandemic. The items were: "To what extent do you think the virus is human made?"; "To what extent do you think the virus is part of a biological warfare program?"; and "To what extent do you think the virus represents an attempt to hurt the Western world?" Participants were asked to rate each belief on a 7-point scale ranging from 1 (not at all) to 7 (very much). The scale displayed excellent internal consistency over all five waves (T1: $\alpha=0.92 ; \mathrm{T} 2$ : $\alpha=0.93$; T3: $\alpha=0.94 ; \mathrm{T} 4: \alpha=0.94 ;$ T5: $\alpha=0.94){ }^{2}$

Analyses. We analysed the data in three steps to maximise the empirical insights. First, before testing our main research question by estimating a more complex multivariate latent growth model, we set out to test univariate latent growth models (LGM; Bollen \& Curran, 2006) to establish whether our data were suitable for this type of analysis. That is, to test whether the variables of interest changed significantly during the COVID-19 pandemic and to determine the shape of this change, we specified a series of univariate latent growth curve models separately for each study variable. Because our goal was to obtain a solution that would represent our data well while being simple enough to be included in the complex multivariate analysis, we started with the simplest solution (nogrowth model with intercept only) and gradually added complexity (linear growth, heteroscedastic residuals, quadratic growth) until the model achieved close fit with the data (i.e. $p_{\text {close }}<.05$ ). For each variable, the first (i.e. the most parsimonious) close-fitting model was retained.

Next, we combined the best-fitting univariate models into one multivariate latent growth model to simultaneously analyse the growth curves of conspiracy

\footnotetext{
2 The survey included other measures that are subject to other research based on this data.
} 
beliefs and social distancing, and their mutual relations over the course of the COVID-19 pandemic. The advantage of multivariate latent growth models is that they allow for the estimation of intercept-slope effects that provide insights into interactions between change processes of two or more constructs. In the present case, they allowed for a test of whether people's initial level of conspiracy beliefs predicted a lower increase in social distancing over time.

Third, to gather complementary insights, we estimated cross-lagged panel models including T1 through T5 conspiracy beliefs and social distancing scores (Finkel, 1995; Selig \& Preacher, 2009). Growth analyses may be complemented with cross-lagged panel models as a way to draw more detailed inferences about the causal order of variables (Schlueter, Davidov, \& Schmidt, 2007). Crosslagged panel models have been criticised for failing to distinguish between within-person and between-person change (Hamaker, Kuiper, \& Grasman, 2015; Mund \& Nestler, 2019). However, in research practice, the more complex alternative statistical approaches such as random intercept cross-lagged models (i.e. RI-CLPM; Hamaker et al., 2015) or autoregressive latent trajectory models (e.g. Mund \& Nestler, 2019) are plagued by convergence issues (Golec de Zavala et al., 2019; Osborne, Milojev, \& Sibley, 2017). Because we were not able to obtain an acceptable solution with these alternative approaches, we used a traditional cross-lagged model to complement our growth analyses.

All analyses were conducted in the R package lavaan 0.6-5 (Rosseel, 2012). In all cases, we accounted for non-normal distributions of the three variables (all Kolmogorov-Smirnov $p s<.001$ ) using robust maximum likelihood (MLR) estimation with Yuan-Bentler scaled $\chi^{2}$ test statistics and Huber-White robust standard errors. We accounted for missing values using full information maximum likelihood estimation, given that they were likely missing at random. Hence, all results are based on the full sample. The complete R code for our analyses is available in SOM.

\section{RESULTS}

Means and bivariate correlations between the study variables are presented in Table 1. Overall, social distancing tended to be negatively related to conspiracy beliefs. Means of social distancing increased across timepoints, while means of conspiracy beliefs tended to decrease, although less consistently.

\section{Univariate and Multivariate Latent Growth Analyses}

Table 2 reports fit indices and comparisons of all univariate models, while Table 3 reports estimates of slope and intercept factors of the retained models. In all models, the intercept was estimated at the first measurement and represents the initial level of the variable. Model 1 (no-growth model) included only the latent intercept factor. Model 2 (linear growth model) included the latent

(C) 2020 The Authors. Applied Psychology: Health and Well-Being published by John Wiley \& Sons Ltd on behalf of International Association of Applied Psychology 


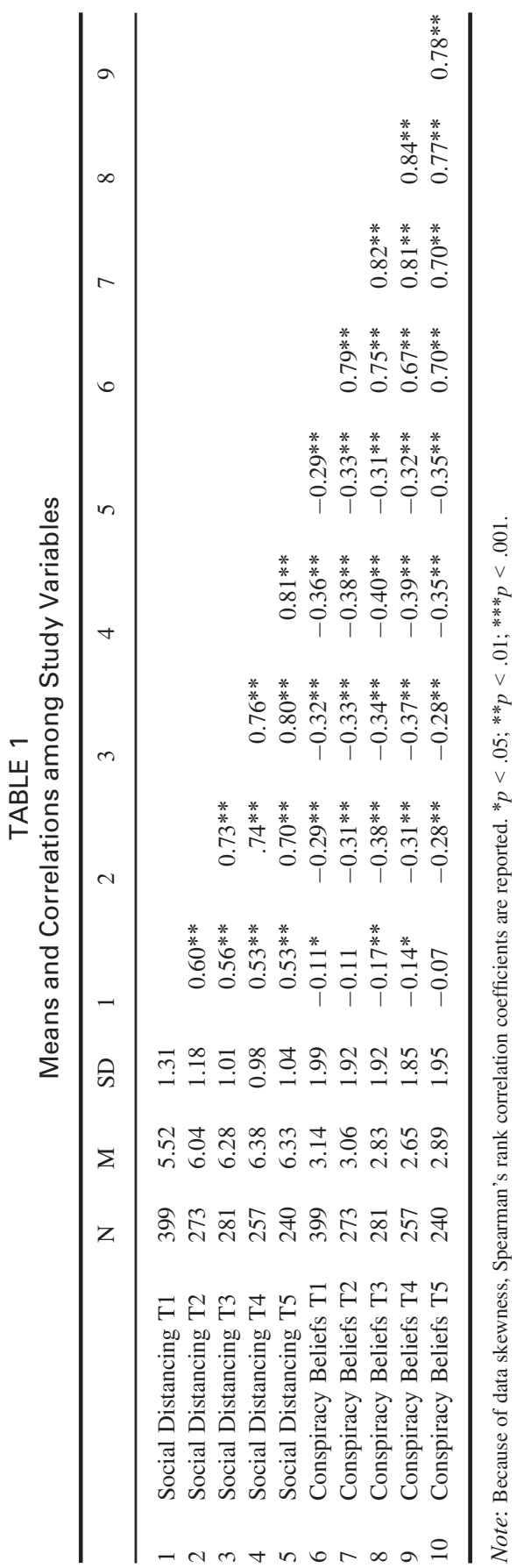

(C) 2020 The Authors. Applied Psychology: Health and Well-Being published by John Wiley \& Sons Ltd on behalf of International Association of Applied Psychology 
TABLE 2

Fit Indices for Univariate Latent Growth Curve Models

\begin{tabular}{|c|c|c|c|c|c|c|c|c|c|c|}
\hline Model & $\chi^{2} / \Delta \chi^{2}$ & $\mathrm{df}$ & $\mathrm{p}$ & CFI & TLI & SRMR & RMSEA & $\begin{array}{l}90 \% \\
\text { CI } \\
\text { low }\end{array}$ & $\begin{array}{l}90 \% \\
\text { CI } \\
\text { high }\end{array}$ & $\mathrm{p}_{\text {close }}$ \\
\hline \multicolumn{11}{|c|}{ Conspiracy Beliefs } \\
\hline Model 1 & 50.177 & 17 & $<.001$ & 0.952 & 0.972 & 0.048 & 0.088 & 0.061 & 0.117 & .032 \\
\hline Model 2 & 20.997 & 14 & .100 & 0.989 & 0.992 & 0.032 & 0.046 & 0.000 & 0.083 & .843 \\
\hline $\begin{array}{l}\text { Model } 1 \\
\text { vs. Model } 2\end{array}$ & 34.205 & 3 & $<.001$ & & & & & & & \\
\hline \multicolumn{11}{|c|}{ Social Distancing } \\
\hline Model 1 & 171.546 & 17 & $<.001$ & $<0.001$ & 0.385 & 0.638 & 0.218 & 0.255 & 0.222 & .291 \\
\hline Model 2 & 80.599 & 14 & $<.001$ & $<0.001$ & 0.714 & 0.796 & 0.121 & 0.192 & 0.153 & .234 \\
\hline $\begin{array}{l}\text { Model } 1 \\
\text { vs. Model } 2\end{array}$ & 133.70 & 3 & $<.001$ & & & & & & & \\
\hline Model 3 & 43.603 & 10 & $<.001$ & 0.914 & 0.914 & 0.083 & 0.125 & 0.088 & 0.164 & $<.001$ \\
\hline $\begin{array}{l}\text { Model } 2 \\
\text { vs. Model } 3\end{array}$ & 27.21 & 4 & $<.001$ & & & & & & & \\
\hline Model 4 & 5.126 & 6 & .010 & 1.000 & 1.003 & 0.032 & 0.000 & 0.000 & 0.075 & $<.001$ \\
\hline $\begin{array}{l}\text { Model } 3 \\
\text { vs. Model } 4\end{array}$ & 32.590 & 4 & $<.001$ & & & & & & & \\
\hline
\end{tabular}

Note: Retained model for each variable is indicated in bold font. Robust fit statistics for each model and robust $\chi^{2}$ difference tests are reported. $p\left(\chi^{2}\right)<.05$ indicates that fit of the model with higher number (e.g. Model 2) was significantly better than the fit of the model with lower number (e.g. Model 1). Model 1—no growth, Model 2-linear growth, homoscedastic residuals; Model 3 - linear growth, heteroscedastic residuals; Model 4 -linear and quadratic growth, heteroscedastic residuals. TLI $>1$ in Model 4 is due to robust adjustment.

TABLE 3

Intercept and Slope Estimates of Retained Univariate Models

\begin{tabular}{lrrrrrr}
\hline & $\mathrm{M}$ & $\mathrm{SE}(\mathrm{M})$ & $\mathrm{p}(\mathrm{M})$ & $\mathrm{S}^{2}$ & $\mathrm{SE}\left(\mathrm{S}^{2}\right)$ & $\mathrm{p}\left(\mathrm{S}^{2}\right)$ \\
\hline $\begin{array}{l}\text { Conspiracy Beliefs } \\
\quad\end{array}$ & & & & & & \\
$\quad$ Intercept & 3.121 & 0.096 & $<.001$ & 3.173 & 0.188 & $<.001$ \\
$\quad$ Linear Slope & -0.048 & 0.023 & .040 & 0.067 & 0.021 & $<.001$ \\
Social Distancing & & & & & & \\
$\quad$ Intercept & 5.559 & 0.066 & $<.001$ & 0.866 & 0.259 & .001 \\
$\quad$ Linear Slope & 0.525 & 0.047 & $<.001$ & 0.137 & 0.147 & .352 \\
$\quad$ Quadratic Slope & -0.085 & 0.010 & $<.001$ & 0.003 & 0.005 & .469 \\
\hline
\end{tabular}

Note: Unstandardised estimates of slope and intercept factors of retained models are reported.

intercept factor and a latent slope factor indicative of linear change. In both models, the residual variance was set to equality for all timepoints (homoscedasticity) for greater parsimony. We then compared both models using scaled $\chi^{2}$ difference

(C) 2020 The Authors. Applied Psychology: Health and Well-Being published by John Wiley \& Sons Ltd on behalf of International Association of Applied Psychology 


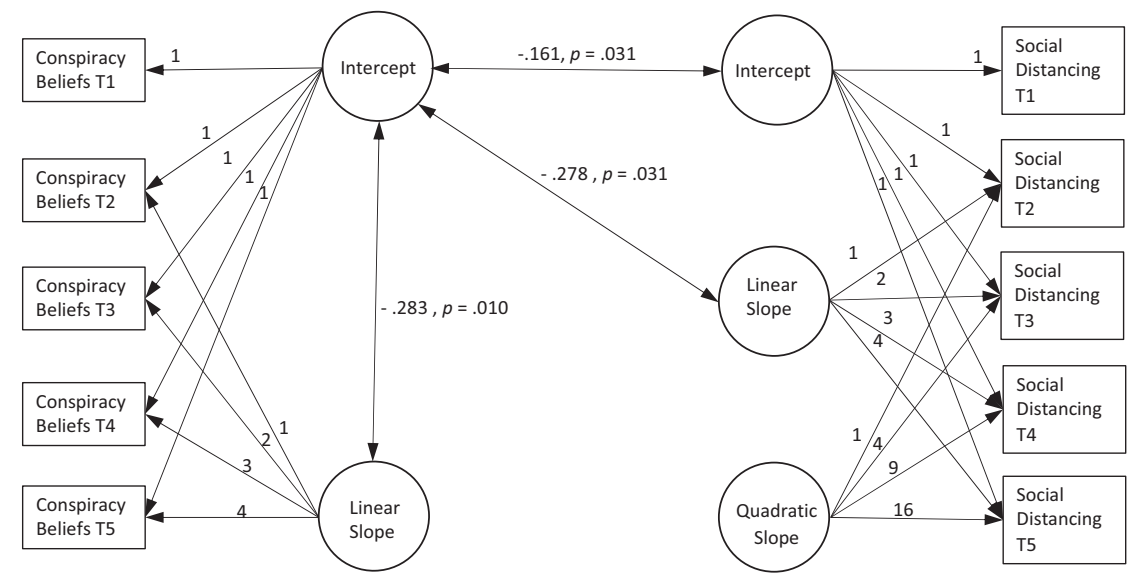

FIGURE 1. Key estimates of the multivariate latent growth model. Note: The figure presents standardised correlation coefficients. The remaining correlations between intercepts and slopes (all ps $>$.17) were estimated but are not presented for the sake of presentational clarity.

tests appropriate for MLR estimation (Table 2). For both social distancing and conspiracy beliefs, model fit improved significantly when linear slope factors were added (Model 2), suggesting that both variables changed across timepoints. For conspiracy beliefs, Model 2 achieved close fit and was retained. This model showed a significant and negative linear slope, suggesting that conspiracy beliefs decreased as the pandemic unfolded. Moreover, the variance of the slope was significant, suggesting that the degree and/or direction of change in conspiracy beliefs varied across participants.

Model 3 included the latent intercept factor and a linear latent slope factor, but this time the residual variance for each timepoint was unconstrained (i.e. allowing for heteroscedasticity). This model showed an improved fit for social distancing. Finally, Model 4 included a quadratic latent slope factor indicative of acceleration/deceleration of change over time, and was otherwise identical to Model 3. This model achieved close fit for social distancing and was retained. The significant positive linear slope factor indicated that social distancing increased as the pandemic unfolded, while the significant negative quadratic slope factor indicated that this increase was the greatest at the beginning of the pandemic and then gradually decelerated.

Next, we estimated the multivariate growth model testing our main research question. Key estimates are presented in Figure 1, whereas detailed results can be found in SOM (Table S2). We observed three correlations between slopes and intercepts. The intercept factor of conspiracy beliefs was weakly and negatively related to the intercept of social distancing, indicating that participants 
who scored higher on conspiracy beliefs at the initial measurement also tended to score lower on social distancing at that time. Crucially, the intercept of conspiracy beliefs was moderately and negatively associated with the slope of social distancing, indicating that participants who reported higher initial levels of conspiracy beliefs tended to show less increase in social distancing over time. In addition to these main findings, the intercept of conspiracy beliefs was weakly and negatively related to its own slope, indicating that higher initial levels of conspiracy beliefs predicted less change in the same variable over time. The remaining associations between intercept factors and slope factors were not significant.

\section{Cross-Lagged Panel Model}

Next, to obtain complementary insights, we estimated a cross-lagged panel model. Here, we regressed the T2 score of each variable on its own T1 value and that of the other variable, the T3 score on its own $\mathrm{T} 2$ value and that of the other variable, and so on. A conservative test of the causal order of variables requires the lagged effects to be the same between all timepoints (Mund \& Nestler, 2019). Therefore, we constrained all auto-regressive paths, all lagged paths between variables, and all within-wave residual correlations between variables to equality between all timepoints. This constrained model showed a close fit to the data, $\chi^{2}(35)=47.746, p=.074, \mathrm{CFI}=0.990 ; \mathrm{TLI}=0.987 ; \mathrm{SRMR}=0.047$; RMSEA $=0.037,90 \%$ CI $[0.006,0.046], p_{\text {close }}=.980$. To ensure that this model was the optimal representation of the data, we additionally tested models with less constraints and we compared them to the fully constrained model. Model fit did not improve significantly when we unconstrained the lagged paths, $\Delta \chi^{2}(6)=9.023, p=.172$, or when we unconstrained both the lagged paths and autoregressions, $\Delta \chi^{2}(12)=11.040, p=.523$. Therefore, we retained the fully constrained model. ${ }^{3}$

Figure 2 presents key estimates of the model, while detailed results can be found in SOM (Table S3). Endorsing conspiracy beliefs at an earlier wave consistently predicted lower levels of social distancing at a later wave. While all lagged effects were weak, please note that these estimates reflect the strength of

\footnotetext{
3 Additionally, to gauge the robustness of the observed effects, we repeated the cross-lagged analysis controlling for age, gender, ethnicity, and education. The model held and the size of effects did not change significantly (see SOM, Table S4, for details). The fully constrained model with covariates and the model with covariates and unconstrained lagged paths showed a similar fit with the data, $\Delta \chi^{2}(6)=7.606, p=.268$. Note that we do not present an analysis with controls for the growth models because such an analysis would require treating them as time invariant covariates. This would be equivalent to testing interactions with intercept and slope factors and thus requires specific predictions and sufficient sample size (given the high number of tests).
}

(C) 2020 The Authors. Applied Psychology: Health and Well-Being published by John Wiley \& Sons Ltd on behalf of International Association of Applied Psychology 


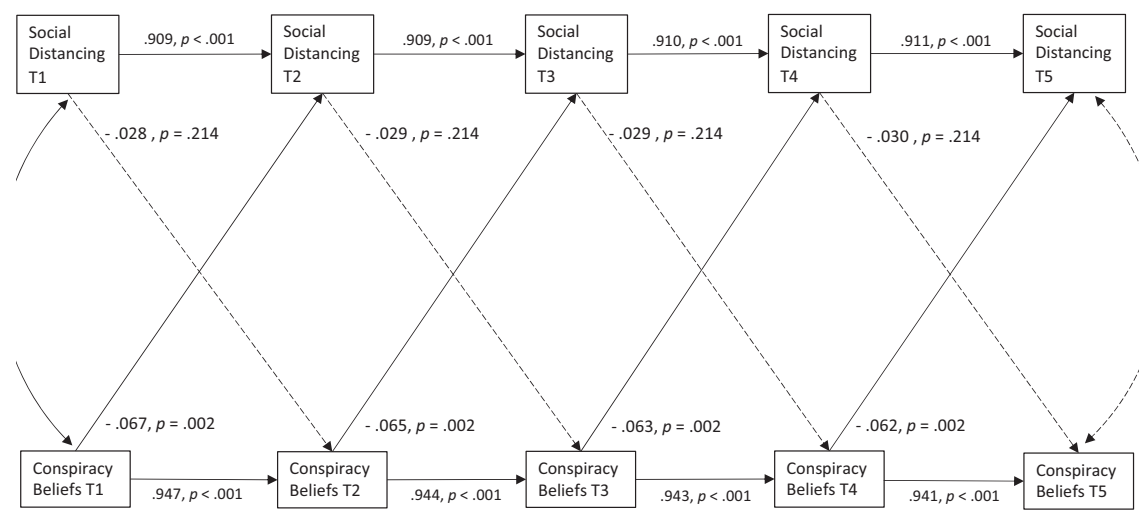

FIGURE 2. Key results of the constrained cross-lagged panel model. Note: The figure presents standardised path coefficients and correlations. Residual correlations for T2, T3, and T4 are identical to T5.

prediction over a very short lag (1-2 weeks) and are highly conservative because of the equality constraint across all waves.

\section{DISCUSSION}

In this study, we explored the dynamic interplay of conspiracy beliefs surrounding the COVID-19 pandemic and social distancing over the course of the six arguably most decisive weeks of the outbreak in the US. Growth curve analyses showed that, although conspiracy beliefs decreased and social distancing increased over time, those holding more conspiracy beliefs at the beginning of the pandemic were those showing the lowest increase in social distancing. Moreover, cross-lagged analyses demonstrated that people who reported more conspiracy beliefs at any wave tended to report less social distancing at the following wave.

These findings are of high theoretical and practical importance. Several studies have shown associations between health-related conspiracy theories and prevention behaviors (Bird \& Bogart, 2005; Gillman et al., 2013; Jolley \& Douglas, 2014b), as well as between conspiracy theories and reduced adherence to government policies (Jolley \& Douglas, 2014a; see also Van Prooijen \& Douglas, 2018). Extending this work, we here provided a longitudinal test of the link between conspiracy beliefs and health-related behavior during a large-scale pandemic. To our knowledge, our study is the first to show these effects using advanced longitudinal modelling that provides insights into causation.

Importantly, a novel contribution of our study is that it shows how belief in conspiracy theories that do not directly and logically put into question a specific 
type of health behavior can still lead to reductions in it. That is, we asked our participants if they believed that the novel coronavirus was bioengineered for a maleficent purpose and we observed effects on social distancing, a behavior that would not appear to be directly linked to the content of this belief. Conspiracy theories may influence people's actions indirectly, for example via feelings of powerlessness that translate into disengaged behaviors (Jolley \& Douglas, 2014a, 2014b). Such a process might have occurred here. People who believe that the pandemic is a product of deliberate actions may feel that they have no power over its outcomes, and, as a consequence, may feel less motivated to socially distance. Another alternative explanation may be that conspiracy theories are correlated; people who believe in one conspiracy theory tend to believe in others, even if they are contradictory (Imhoff \& Bruder, 2014; Van Prooijen \& Douglas, 2018; see also Imhoff \& Lamberty, 2020). Thus, in the present case, participants who believed that the coronavirus was bioengineered may also believe that the pandemic is not real, which would explain their reluctance to engage in social distancing. Lastly, it is also possible that people who believe in such conspiracy beliefs, which ultimately involve the perception of an external threat to their nation, may seek social support, leading them to maintain contact with others to a greater extent. However, as future research is needed to directly establish the role of this and other potential mediators, such an explanation remains speculative at this point.

One unexpected finding was that conspiracy beliefs decreased over the course of the outbreak. It is yet unknown whether the development of conspiracy theories follows any systematic trajectory during societal crises. However, it seems reasonable to suspect that they peak at the beginning and then slow down as people adapt to the new situation (cf. Norris, Tracy, \& Galea, 2009). Since conspiracy theories appeared nearly simultaneously with the virus, their peak might have preceded our data collection and we may only have captured the decrease during an adaptation period. Intuitively, one may argue that, as cases and casualties increased, including within people's immediate surroundings, many obtained first-hand evidence of the pandemic that was hard to reconcile with some of their theories. Yet, this may not explain the decrease of belief in the specific theories we measured (e.g. that the virus was man-made), which did not deny the existence of the pandemic per se. Still, it is possible that, as the severity of the pandemic's impact in the US increased, participants relied more on established news and information sources, leading to a change in their beliefs. Future research may clarify these processes by including objective data, such as media information, political statements, infection level or exposure level, to identify and explain the trajectories of conspiracy theories during this and other societal crises. 


\section{Limitations}

While our results suggest that belief in conspiracy theories reduces social distancing, it is important to note that longitudinal models allow for establishing only two out of three necessary conditions of causation, that is, (1) temporal precedence and (2) association between cause and effect over time (Selig \& Little, 2012). They do not satisfy the third necessary condition, that is, exclusion of alternative causes, unless all possible confounders are accounted for in the analysis (see, for example, Pearl, 2014), which is rarely possible. Thus, even robust longitudinal effects such as those observed in the current study should be treated as evidence in favor of causation rather than evidence demonstrating causation (Selig \& Little, 2012). Future research may, therefore, profitably test for potential confounders of the relationship between conspiracy beliefs and health-related behaviors (e.g. health literacy).

Although the effects in the cross-lagged analysis were weak by conventional standards, please note that they referred to a very short time interval (1-2 weeks) and one could expect that a cumulative effect over a longer time period would be stronger. Indeed, such an assumption would be in line with the growth model that showed a much stronger, medium-sized association between initial levels of conspiracy beliefs and the overall trajectory of social distancing over the entire 6 weeks of the study.

\section{Practical Implications}

Our findings clearly show that COVID-19 conspiracy theories are a threat to public health, even if they do not deny the very existence of the pandemic. Throughout the outbreak, such theories were deliberately nourished by politicians, media, and even the scientific community, and, as our research suggests, their consequences were likely disastrous. To date, the US is the country with the greatest number of deaths caused by COVID-19 (WHO, 2020b), and in light of our findings, conspiracy beliefs likely contributed to this. To ensure high adherence to social distancing, which remains the most effective means to reduce the spread of the virus, and the effective prevention of future pandemics and other societal crises, media stakeholders, policy makers, and politicians should collectively work to counter such theories from the beginning.

\section{REFERENCES}

Bale, J.M. (2007). Political paranoia v. political realism: On distinguishing between bogus conspiracy theories and genuine conspiratorial politics. Patterns of Prejudice, 41, 4560. https://doi.org/10.1080/00313220601118751

BBC News (2020a, 8 February). Coronavirus: WHO chief warns against "trolls and conspiracy theories". https://www.bbc.com/news/world-51429400

(C) 2020 The Authors. Applied Psychology: Health and Well-Being published by John Wiley \& Sons Ltd on behalf of International Association of Applied Psychology 
BBC News (2020b, 1 May). Coronavirus: Trump stands by China lab origin theory for virus. https://www.bbc.com/news/world-us-canada-52496098

Bird, S.T., \& Bogart, L.M. (2005). Conspiracy beliefs about HIV/AIDS and birth control among African Americans: Implications for the prevention of HIV, other STIs, and unintended pregnancy. Journal of Social Issues, 61(1), 109-126. https://doi.org/10. 1111/j.0022-4537.2005.00396.x

Bollen, K.A., \& Curran, P.J. (2006). Latent curve models: A structural equation perspective. New York: John Wiley \& Sons.

European Parliament (2020, 19 May). Public opinion monitoring at a glance in the times of COVID-19. https://www.europarl.europa.eu/at-your-service/files/be-heard/euroba rometer/2020/covid19/en-public-opinion-in-the-time-of-covid19-20200519.pdf

Finkel, S.E. (1995). Causal analysis with panel data. In M.S. Lewis-Beck (Ed.), Quantitative applications in the social sciences. Thousand Oaks, CA: Sage Publications.

Gillman, J., Davila, J., Sansgiry, S., Parkinson-Windross, D., Miertschin, N., Mitts, B., ... Giordano, T.P. (2013). The effect of conspiracy beliefs and trust on HIV diagnosis, linkage, and retention in young MSM with HIV. Journal of Health Care for the Poor and Underserved, 24(1), 36-45. https://doi.org/10.1353/hpu.2013.0012

Golec de Zavala, A., Federico, C.M., Sedikides, C., Guerra, R., Lantos, D., Mroziński, B., ... Baran, T. (2019). Low self-esteem predicts out-group derogation via collective narcissism, but this relationship is obscured by in-group satisfaction. Journal of Personality and Social Psychology, 119(3), 741-764.

Haffajee, R.L., \& Mello, M.M. (2020). Thinking globally, acting locally-The US response to COVID-19. New England Journal of Medicine, 382(22), e75. https://doi. org/10.1056/NEJMp2006740

Hamaker, E.L., Kuiper, R.M., \& Grasman, R.P.P.P. (2015). A critique of the cross-lagged panel model. Psychological Methods, 20(1), 102-116. https://doi.org/10.1037/ a0038889

Hertzog, C., Lindenberger, U., Ghisletta, P., \& von Oertzen, T. (2006). On the power of multivariate latent growth curve models to detect correlated change. Psychological Methods, 11(3), 244-252.

Imhoff, R., \& Bruder, M. (2014). Speaking (un-)truth to power: Conspiracy mentality as a generalized political attitude. European Journal of Personality, 28, 25-43. https://doi. org/10.1002/per.1930

Imhoff, R., \& Lamberty, P. (2020). A bioweapon or a hoax? The link between distinct conspiracy beliefs about the Coronavirus disease (COVID-19) outbreak and pandemic behavior. Social Psychological and Personality Science. https://psyarxiv.com/ye3ma/d ownload?format=pdf

Jolley, D., \& Douglas, K. (2014a). The social consequences of conspiracism: Exposure to conspiracy theories decreases intentions to engage in politics and to reduce one's carbon footprints. British Journal of Psychology, 105, 35-56. https://doi.org/10.1111/ bjop. 12018

Jolley, D., \& Douglas, K.M. (2014b). The effects of anti-vaccine conspiracy theories on vaccination intentions. PLoS One, 9, e89177. https://doi.org/10.1371/journal.pone. 0089177 
McCarthy, J. (2020, 8 April).Three in four in US have self-isolated in their household. Gallup. https://news.gallup.com/poll/307760/three-four-self-isolated-household.aspx

Meier, K., Glatz, T., Guijt, M.C., Piccininni, M., van der Meulen, M., Atmar, K., ... Najafabadi, A.H.Z., \& COVID-19 Survey Study Group (2020). Public perspectives on social distancing and other protective measures in Europe: A cross-sectional survey study during the COVID-19 pandemic. 10.1101/2020.04.02.20049676

Mund, M., \& Nestler, S. (2019). Beyond the cross-lagged panel model: Next-generation statistical tools for analyzing interdependencies across the life course. Advances in Life Course Research, 41, 100249. https://doi.org/10.1016/j.alcr.2018.10.002

Nature (2020). Editor's note. Retrieved 25 March 2020 from: https://www.nature.com/ne ws/inside-the-chinese-lab-poised-to-study-world-s-most-dangerous-pathogens-1.21487

Norris, F.H., Tracy, M., \& Galea, S. (2009). Looking for resilience: Understanding the longitudinal trajectories of responses to stress. Social Science \& Medicine, 68(12), 2190-2198. https://doi.org/10.1016/j.socscimed.2009.03.043

Osborne, D., Milojev, P., \& Sibley, C.G. (2017). Authoritarianism and national identity: Examining the longitudinal effects of SDO and RWA on nationalism and patriotism. Personality and Social Psychology, 43(8), 1086-1099. https://doi.org/10.1177/ 0146167217704196

Pearl, J. (2014). Interpretation and identification of causal mediation. Psychological Methods, 19(4), 459-481. https://doi.org/10.1037/a0036434

Rosseel, Y. (2012). lavaan: An R package for structural equation modeling. Journal of Statistical Software, 48(2), 1-36. http://www.jstatsoft.org/v48/i02/

Sandford, A. (2020, 3 April). Coronavirus: Half of humanity now on lockdown as 90 countries call for confinement. Euronews.https://www.euronews.com/2020/04/02/c oronavirus-in-europe-spain-s-death-toll-hits-10-000-after-record-950-new-deaths-in24-hou

Schlueter, E., Davidov, E., \& Schmidt, P. (2007). Applying autoregressive cross-lagged and latent growth curve models to a three-wave panel study. In K. van Montfort, J. Oud, \& A. Satorra (Eds.), Longitudinal models in the behavioral and related sciences (pp. 315-336). Hillsdale, NJ: Lawrence Erlbaum Associates.

Selig, J.P., \& Little, T.D. (2012). Autoregressive and cross-lagged panel analysis for longitudinal data. In B. Laursen, T.D. Little, \& N.A. Card (Eds.), Handbook of developmental research methods (pp. 265-278). New York: The Guilford Press.

Selig, J.P., \& Preacher, K.J. (2009). Mediation models for longitudinal data in developmental research. Research in Human Development, 6(2-3), 144-164. https://doi.org/ $10.1080 / 15427600902911247$

Sheikh, K. (2020, 16 March). No more than 10 people in one place, Trump said. But why? The New York Times. https://www.nytimes.com/2020/03/16/health/coronavirussocial-distancing-crowd-size.html

Swami, V., \& Barron, D. (2020). Analytic thinking, rejection of coronavirus (COVID-19) conspiracy theories, and compliance with mandated social-distancing: Direct and indirect relationships in a nationally representative sample of adults in the United Kingdom. https://doi.org/10.31219/osf.io/nmx9w

Uscinski, J.E., \& Enders, A.M. (2020, 30 April). The Coronavirus conspiracy boom. The Atlantic. https://www.theatlantic.com/health/archive/2020/04/what-can-coronavirus-te 11-us-about-conspiracy-theories/610894/

(C) 2020 The Authors. Applied Psychology: Health and Well-Being published by John Wiley \& Sons Ltd on behalf of International Association of Applied Psychology 
Van Bavel, J.J., Baicker, K., Boggio, P.S., Capraro, V., Cichocka, A., Cikara, M., ... Drury, J. (2020). Using social and behavioural science to support COVID-19 pandemic response. Nature Human Behaviour, 4(5), 460-471, https://doi.org/10.1038/ s41562-020-0884-z

Van Prooijen, J.-W., \& Douglas, K.M. (2017). Conspiracy theories as part of history: The role of societal crisis situations. Memory Studies, 10, 323-333. https://doi.org/10.1177/ 1750698017701615

Van Prooijen, J.-W., \& Douglas, K.M. (2018). Belief in conspiracy theories: Basic principles of an emerging research domain. European Journal of Social Psychology, 48(7), 897-908. https://doi.org/10.1002/ejsp.2530

Wahl, I., Kastlunger, B., \& Kirchler, E. (2010). Trust in authorities and power to enforce tax compliance: An empirical analysis of the "Slippery Slope Framework". Law \& Policy, 32(4), 383-406. https://doi.org/10.1111/j.1467-9930.2010.00327.x

World Health Organization (2020a, 5 March). Coronavirus disease 2019 (COVID-19) situation report 45. https://www.who.int/docs/default-source/coronaviruse/situationreports/20200305-sitrep-45-covid-19.pdf?sfvrsn=ed2ba78b_4

World Health Organization. (2020b, 26 May). Coronavirus disease 2019 (COVID-19) situation report 127. https://www.who.int/docs/default-source/coronaviruse/situationreports/20200526-covid-19-sitrep-127.pdf?sfvrsn=7b6655ab_8

Zhang, Z. (2014). Monte Carlo based statistical power analysis for mediation models: Methods and software. Behavior Research Methods, 46, 1184-1198. https://doi.org/ 10.3758/s13428-013-0424-0

\section{SUPPORTING INFORMATION}

Additional supporting information may be found online in the Supporting Information section at the end of the article.

Table S1. Demographics the Sample.

Table S2. Estimates of the Multivariate Latent Growth Model.

Table S3. Estimates of the Cross-Lagged Panel Model.

Table S4. Estimates of the Cross-Lagged Panel Model with Covariates.

Supplementary Material.

(C) 2020 The Authors. Applied Psychology: Health and Well-Being published by John Wiley \& Sons Ltd on behalf of International Association of Applied Psychology 